\title{
Pengaruh Teknologi Informasi Terhadap Pengembangan Potensi Dan Kinerja Pegawai Di BPMDES Kabupaten Bima
}

\author{
Marhaen \\ Sekolah Tinggi Ilmu Ekonomi Bima \\ marhaen17.stiebima@email.com

\section{Jaenab} \\ Sekolah Tinggi Ilmu Ekonomi Bima \\ jaenab.stiebima@email.com
}

\begin{abstract}
Abstrak
Penelitian ini bertujuan untuk mengetahui pengaruh teknologi informasi terhadap pengembangan potensi dan kinerja pegawai di BPMDES Kabupaten Bima. Penelitian ini berjenis asosiatif, penelitian dilakukan melalui pengisian pertanyaan oleh pegawai KPP di BPMDES Kabupaten Bima. Populasi yang digunakan yaitu seluruh pegawai yang bekerja di BPMDES Kabupaten Bima yang berjumlah 71 orang terdiri dari 15 orang Honorer daerah, 12 orang sukarela dan 44 orang ASN. Teknik sampling yang peneliti gunakan dalam penelitian ini adalah tehnik nonprobability sampling, tehnik sampling ini memberi peluang yang sama bagi setiap unsur atau anggota populasi untuk di pilih menjadi sampel. Jenis data yang digunakan yaitu data primer dan data sekunder, instrumen penelitian yang digunakan dalam penelitian ini adalah kuesioner dengan skala likert. Teknik pengumpulan data yang digunakan yang digunakan yaitu observasi, kuesioner dan studi pustaka, teknik analisa data yang digunakan yaitu uji validitas, uji reliabilitas, uji asumsi klasik, analisis regresi linera sederhana, koefisien korelasi sederhana, uji determinasi, uji t dan uji f. Hasil penelitian ini menunjukkan teknologi informasi berpengaruh signifikan terhadap pengembangan potensi dan kinerja pegawai di BPMDES Kabupaten Bima dengan tingkat hubungan teknologi informasi terhadap pengembangan potensi pegawai di BPMDES Kabupaten Bima adalah kuat, sedangkan tingkat hubungan teknologi informasi terhadap kinerja pegawai di BPMDES Kabupaten Bima adalah rendah.
\end{abstract}

Kata Kunci Teknologi Informasi, Pengembangan Potensi, Kinerja Pegawai

\section{PENDAHULUAN}

Era globalisasi saat ini hampir semua instansi telah membuka mata dengan memberikan perhatian terhadap perkembangan teknologi informasi. Berkat kemajuan teknologi komunikasi dan informasi, hubungan antar negara, anatar organisasi, dan antar individu, terasa seperti tidak berjarak. Kemajuan ini memberikan dampak terhadap organisasi atau instansi untuk berupaya konvensional, seiring dengan perkembangan teknologi informasi yang begitu pesat maka organisasipun dituntut untuk bersaing secara 
kompetitif, agar kebutuhan manajemen dapat bekerja secara efektif dan efisien. Disinilah informasi memegang peranan penting dikarenakan informasi dibutuhkan oleh semua pihak, baik individu maupun organisasi atau instansi.

Kehidupan masyarakat yang semakin kompleks menuntut adanya suatu pelayanan yang semakin berkualitas, yang mana dalam hal ini pemerintah sebagai provider atau penyedia harus lebih intensif didalam memperhatikan pelayanan tersebut. Karena diberbagai kesempatan pemerintah senantiasa menjanjikan pelayanan yang memuaskan kepada masyarakat, namun dalam kenyataannya belum dilaksanakan secara optimal.

Pendekatan yang dapat digunakan dalam upaya memperbaiki kualitas penyelenggaraan pelayanan kepada masyarakat adalah pendekatan yang dilihat dari aspek manusia dan juga dari aspek pendukung manusia dalam menjalankan pekerjaannya dalam hal ini berupa teknologi informasi. Salah satu faktor utamanya adalah kemampuan manusia dalam melakukan pekerjaannya dan faktor pendukung adalah teknologi informasi.

Prasojo dan Riyanto dalam (Wahyuni, 2018) menyatakan bahwa teknologi informasi diartikan sebagai ilmu pengetahuan dalam bidang informasi yang berbasis komputer dan perkembanganya sangat pesat.

Muzakki, et.al., (2016) juga berpendapat bahwa teknologi informasi adalah suatu teknologi yang digunakan untuk mengolah data. Pengolahan itu termasuk memproses, mendapatkan, menyusun, menyimpan, memanipulasi data dalam berbagai cara untuk menghasilkan informasi yang berkualitas, yaitu informasi yang relevan, akurat dan tepat waktu. Teknologi informasi saat ini menjadi hal yang sangat penting bagi banyak organisasi karena manfaatnya telah dirasakan dapat membantu mempermudah dalam mendukung aktivitas organisasi, teknologi informasi mendukung proses pengelolaan informasi karena dapat meningkatkan kompleksitas tugas manajemen, mempengaruhi ekonomi internasional (globalisasi), mempercepat waktu tanggap (response time) dan mengurangi tekanan dari pihak luar. Teknologi telah didesain untuk menunjang pekerjaan manusia menuju efisiensi praktis tepat guna. membantu dalam mengelola data organisasi dan mempermudah dalam menginput data taransaksi, hal inilah yang mampu memberikan dampak terhadap pengembangan potensi maupun kinerja pegawai pada suatu organisasi atau instansi.

Pengembangan potensi merupakan kemampuan dasar yang dimiliki manusia yang masih terpendam didalam dirinya yang menunggu untuk diwujudkan menjadi suatu manfaat nyata dalam kehidupan diri manusia dan memiliki kemungkinan untuk dikembangkan jika dilatih dan ditunjang dengan baik (Nurariansyah, 2019). Pengembangan diri yang merupakan proses yang komprehensif dari awal keputusan sampai menuju puncak sukses dalam meraih kemandirian suatu organisasi. Perkembangan berarti serangkaian perubahan progresif yang terjadi karena proses kematangan dan pengalaman. Setiap individu dalam pengembangan dirinya pasti tidak terlepas dari berbagai faktor, baik intern maupun ekstern.

Sedangkan kinerja pegawai adalah hasil pencapaian seseorang menurut ukuran yang berlaku untuk suatu pekerjaan atau berdasarkan standar kerja dalam periode tertentu. Menurut Kaswan dalam (Supriatna dan Sutisna, 2019) kinerja adalah kemampuan pegawai untuk melakukan pekerjaan yang mungkin di tingkatkan dengan menekankan pada kelebihannya dan pemahaman terhadap perubahan-perubahan apa yang dibutuhkan. Kinerja dalam suatu organisasi dilakukan oleh segenap sumber daya manusia dalam organisasi, baik unsur pimpinan maupun pekerja. 
Berdasarkan uraian diatas dapat dilihat betapa penting nya peranan teknologi informasi bagi pegawai diberbagai instansi pemerintahan, dari penelitian awal yang dilakukan pada kualitas potensi dan kinerja dari aparatur sipil negara di BPMDES Kabupaten Bima dapat diketahui bahwa tingkat pengetahuan akan teknologi informasi pada pegawai belum di terapkan secara maksimal dan cenderung rendah, semuanya bisa di nilai dan di lihat dari pegawai yang cenderung lambat dalam meng-input data keperluan masyarakat serta kurang efisien nya pelayanan pegawai pada saat masyarakat meminta data informasi dan masyarakat di suruh menunggu berjam-jam, Berdasarkan fenomena yang terjadi, penulis tertarik mengambil penelitian yang berjudul "Pengaruh Teknologi Informasi Terhadap Pengembangan Potensi Dan Kinerja Pada Pegawai Di BPMDES Kabupaten Bima" dengan menggunakan metode-metode dan pengujian secara sistematis, sehingga pokok permasalahan mampu di uraikan dan di jelaskan secara terperinci.

\section{LANDASAN TEORI}

\section{A. Teknologi Infomasi}

Mulyadi dalam (Permata et al., 2017) mengemukakan bahwa teknologi informasi adalah mencakup komputer (baik perangkat lunak), berbagai peralatan kantor elektronik, perlengkapan pabrik dan telekomunikasi. Sedangkan menurut Purbo (2018:334) teknologi adalah kemampuan untuk memahami kelengkapan yang mengikuti teknologi seperti peranti keras (hardware), peranti lunak (software), serta etika dan etiket dalam memanfaatkan teknologi.

Dari penjelasan di atas dapat disimpulkan bahwa teknologi informasi adalah teknologi hasil karya manusia yang mengkombinasikan komputer dengan saluran komunikasi berkecepatan tinggi yang digunakan dalam proses penyampaian informasi (data, suara, vidio) sehingga penyebaran informasi lebih cepat, lebih luas dan lebih lama penyimpanannya.

\section{B. Pengembangan Potensi}

Menurut Widodo dalam (Nurhasannah, 2017) potensi diri merupakan kemampuan dasar dari sesuatu yang masih terpendam di dalamnya yang menunggu untuk diwujudkan menjadi suatu kekuatan nyata. Artinya, potensi diri manusia adalah kemampuan dasar yang dimiliki manusia yang masih terpendam di dalam dirinya, yang menunggu stimulus untuk diwujudkan.

Jadi potensi diri adalah kemampuan atau kekuatan yang ada dalam setiap orang baik fisik maupun mental dan memungkinkan untuk dioptimalkankan bila dilatih dengan konsisten dan baik. Sehingga bisa disimpulkan bahwa potensi diri adalah kemampuan, kekuatan, dan daya yang ada di setiap orang yang bisa dimunculkan untuk berbagai kepentingan dan keperluan kehidupan manusia.

\section{Kinerja Pegawai}

Dalam suatu organisasi, hal yang mendasar untuk membawa organisasi kearah yang lebih baik adalah sumber daya manusianya, atau para pegawai yang ada didalamnya, pegawai yang memiliki kualitas kerja yang baik tentu akan membawa dampak yang baik pula untuk organisasi. Hasibuan (2016) menyatakan "kinerja adalah suatu hasil kerja yang dicapai seseorang dalam melaksanakan tugas tugas yang dibebankan kepadanya yang didasarkan atas kecakapan, pengalaman, kesungguhan serta waktu”. 
Menurut Mangkunegara dalam (Pristyadi dan Santoso, 2019) pengertian kinerja adalah hasil kerja secara kualitas dan kuantitas yang dicapai oleh seorang pegawai dalam melaksanakan tugasnya sesuai dengan tanggung jawab yang diberikan kepadanya.

\section{METODOLOGI PENELITIAN}

Penelitian ini dilakukan dengan berbagai langkah kerja yang sistematis sehingga mendapatkan hasil yang optimal. Langkah kerja penelitian merupakan serangkaian prosedur dan langkah - langkah dalam melakukan penelitian yang terstruktur secara sistematis dan terarah agar tujuan dari penelitian bisa tercapai dengan baik. Adapun langkah-langkah yang digunakan dalam penelitian ini dilihat dalam flowchart penelitian.

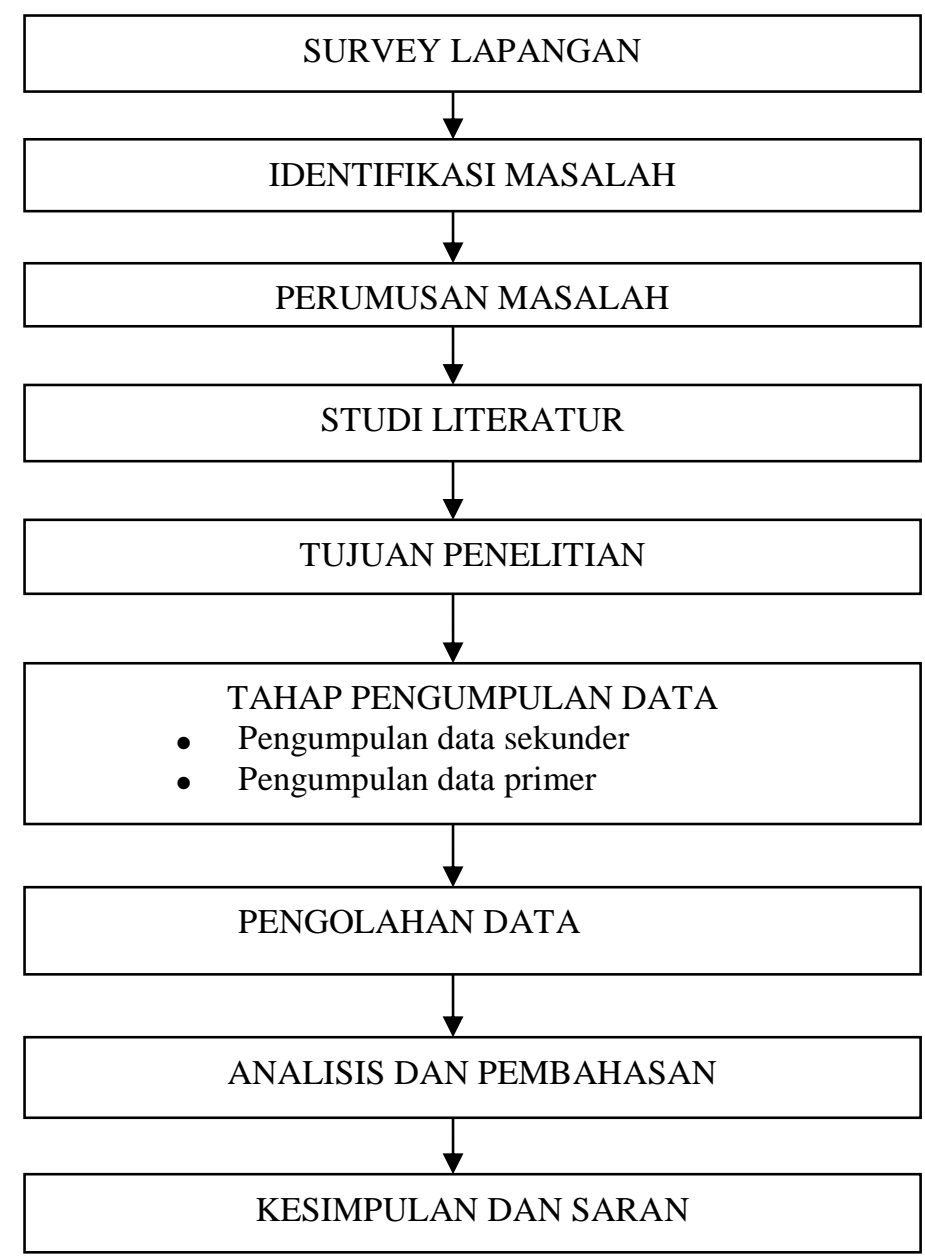

Gambar 1. Flow Chart

\section{HASIL PENELITIAN}

a. Uji Validitas

Tabel 1. Hasil Uji Validitas

\begin{tabular}{llll}
\hline Variabel dan Item & R hitung & R table & Keterangan \\
\hline
\end{tabular}




\begin{tabular}{cccc}
\hline Teknologi Informasi (X) & & & \\
\hline X1 & 0,760 & 0,300 & Valid \\
\hline X2 & 0,460 & 0,300 & Valid \\
\hline X3 & 0,636 & 0,300 & Valid \\
\hline X5 & 0,760 & 0,300 & Valid \\
\hline Pengembangan Potensial (Y1) & 0,636 & 0,304 & Valid \\
\hline Y1.1 & 0,476 & 0,304 & Valid \\
\hline Y1.2 & 0,677 & 0,304 & Valid \\
\hline Y1.3 & 0,625 & 0,304 & Valid \\
\hline Y1.4 & 0,393 & 0,304 & Valid \\
\hline Y1.5 & 0,415 & 0,304 & Valid \\
\hline Kinerja pegawai (Y2) & & & \\
\hline Y2.1 & 0,362 & 0,304 & Valid \\
\hline Y2.2 & 0,726 & 0,304 & Valid \\
\hline Y2.3 & 0,726 & 0,304 & Valid \\
\hline Y2.4 & 0,316 & 0,304 & Valid \\
\hline Y2.5 & 0,515 & 0,304 & Valid
\end{tabular}

Sumber : data diolah dengan SPSS v20

Dari tabel diatas dapat dilihat bahwa seluruh instrument dalam penelitian ini memiliki nilai validitas $>0,304$. Sehingga instrument dalam penelitian ini dikatakan valid dan layak digunakan dalam penelitian.

b. Uji Reliabilitas

Tabel 2. Hasil Uji Reliabilitas

\begin{tabular}{lccc}
\hline \multicolumn{1}{c}{ Variabel } & $\begin{array}{c}\text { Cronbach's } \\
\text { Alpha }\end{array}$ & $\begin{array}{c}\text { Standar } \\
\text { Reliabel }\end{array}$ & Keterangan \\
\hline Teknologi Informasi & 0,62 & $>0,60$ & Reliabel \\
\hline $\begin{array}{l}\text { Pengembangan } \\
\text { Potensi }\end{array}$ & 0,93 & $>0,60$ & Reliabel \\
\hline Kinerjapegawai & 0,69 & $>0,60$ & Reliabel \\
\hline
\end{tabular}

Sumber : data diolah dengan SPSS v20

Metode uji reliabilitas yang digunakan pada penelitian yaitu membandingkan nilai Cronbach's Alpha dengan standar reliabilitas, item dikatakan reliabel apabila nilai dari Cronbach's Alpha $>0,60$. Dari tabel diatas dapat dilihat bahwa seluruh instrument dalam penelitian ini memiliki nilai alpha $>0,6$, sehingga instrument dalam penelitian ini memenuhi standar reliable dan dapat digunakan dalam penelitian ini.

\section{c. Uji Asumsi Klasik}

\section{Uji Nomalitas}

Pada penelitian ini untuk uji normalitas menggunakan uji One-Sample Kolmograv-Smirnov Test dengan menggunakan taraf signifikan 0,05, suatu data dinyatakan berdistribusi normal apabila nilai Asymp. Sig > 0,05.

Tabel 3. Hasil Uji Normalitas Variabel Tekhnologi Informasi terhadap Pengembangan Potensi 


\begin{tabular}{|c|c|c|}
\hline \multicolumn{3}{|c|}{ One-Sample Kolmogorov-Smirnov Test } \\
\hline & & $\begin{array}{c}\text { Unstandardi } \\
\text { zed } \\
\text { Residual }\end{array}$ \\
\hline $\mathrm{N}$ & & 42 \\
\hline \multirow[t]{2}{*}{ Normal Parameters ${ }^{\mathrm{a}, \mathrm{b}}$} & Mean & 0E-7 \\
\hline & $\begin{array}{l}\text { Std. } \\
\text { Deviation }\end{array}$ & .97702818 \\
\hline \multirow{3}{*}{$\begin{array}{l}\text { Most Extreme } \\
\text { Differences }\end{array}$} & Absolute & .195 \\
\hline & Positive & .127 \\
\hline & Negative & -.195 \\
\hline \multicolumn{2}{|c|}{ Kolmogorov-Smirnov Z } & 1.266 \\
\hline \multicolumn{2}{|c|}{ Asymp. Sig. (2-tailed) } & .081 \\
\hline \multicolumn{3}{|c|}{ a. Test distribution is Normal. } \\
\hline
\end{tabular}

Sumber : data diolah dengan SPSS v20

Berdasarkan tabel uji One-Sample Kolmograv-Smirnov Test diatas diketahui nilai Asymp. Sig sebesar 0,081 >0,05, dapat disimpulkan bahwa data berdistribusi normal.

Tabel 4. Hasil Uji Normalitas Variabel Tekhnologi Informasi terhadap Kinerja Pegawai

\begin{tabular}{|c|c|c|}
\hline \multicolumn{3}{|c|}{ One-Sample Kolmogorov-Smirnov Test } \\
\hline & & $\begin{array}{c}\text { Unstandardi } \\
\text { zed } \\
\text { Residual }\end{array}$ \\
\hline $\mathrm{N}$ & & 42 \\
\hline \multirow[t]{2}{*}{ Normal Parameters ${ }^{\mathrm{a}, \mathrm{b}}$} & Mean & 0E-7 \\
\hline & $\begin{array}{l}\text { Std. } \\
\text { Deviation }\end{array}$ & 1.24296774 \\
\hline \multirow{3}{*}{$\begin{array}{l}\text { Most Extreme } \\
\text { Differences }\end{array}$} & Absolute & .115 \\
\hline & Positive & .096 \\
\hline & Negative & -.115 \\
\hline \multicolumn{2}{|c|}{ Kolmogorov-Smirnov Z } & .745 \\
\hline \multicolumn{2}{|l|}{ Asymp. Sig. (2-tailed) } & .636 \\
\hline \multicolumn{3}{|c|}{ a. Test distribution is Normal. } \\
\hline \multicolumn{2}{|c|}{ b. Calculated from data. } & \\
\hline
\end{tabular}

Berdasarkan tabel uji One-Sample Kolmograv-Smirnov Test diatas diketahui nilai Asymp. Sig sebesar 0,636>0,05, dapat disimpulkan bahwa data berdistribusi normal.

\section{Uji Heterokedastisitas}

Berikut hasil uji pada grafik Scatterplot teknologi informasi terhadap pengembangan potensi dan kinerja pegawai : 


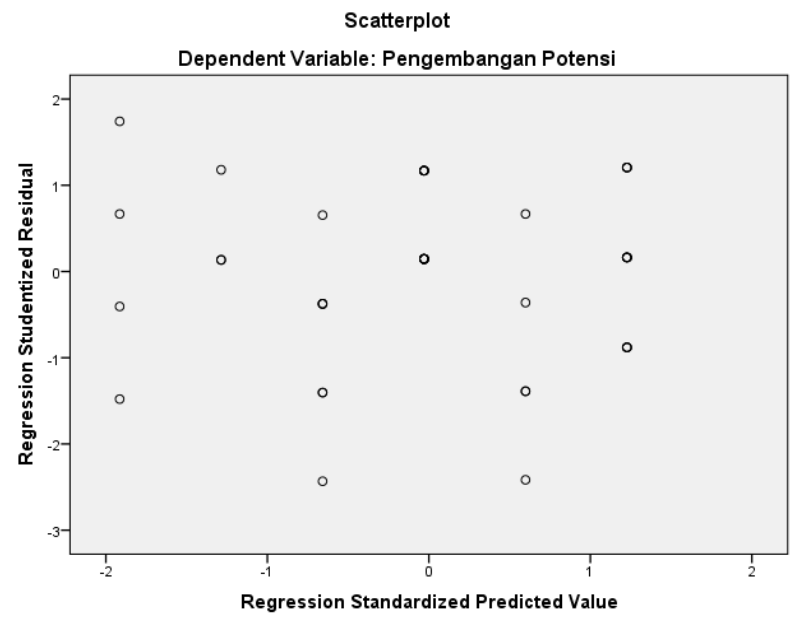

Gambar 2. Uji Heterokedastisitas

Berdasarkan outputs SPSS pada gambar Scatterplot diatas menunjukan bahwa penyebaran residual adalah tidak teratur dan tidak membentuk pola. Hal tersebut dapat dilihat pada titik-titik atau plot yang menyebar. Sehingga dapat disimpulkan yang dapat diambil adalah bahwa tidak terjadi residual.

\section{d. Analisis Regresi Linear Sederhana}

Tabel 5. Hasil Analisis Regresi Linear Variabel Tekhnologi Informasi terhadap Pengembangan Potensi

\begin{tabular}{llrrc}
\hline \multicolumn{4}{c}{ Coefficients $^{\mathbf{a}}$} \\
\hline Model & \multicolumn{2}{c}{$\begin{array}{c}\text { Unstandardized } \\
\text { Coefficients }\end{array}$} & $\begin{array}{c}\text { Standardize } \\
\mathrm{d} \\
\text { Coefficients }\end{array}$ \\
\cline { 3 - 5 } & & $\mathrm{B}$ & Std. Error & Beta \\
\hline \multirow{2}{*}{1} & (Constant) & 11.516 & 2.242 & \\
\cline { 2 - 5 } & Teknologi & .493 & .097 & .626 \\
& Informasi & & & \\
\hline
\end{tabular}

a. Dependent Variable: Pengembangan Potensi

Sumber : data diolah dengan SPSS v20

Berdasarkan hasil output SPSS diatas maka persamaan regresi linear sederhananya dapat dirumus kan sebagai berikut :

$\mathrm{Y} 1=11,516+0,493 \mathrm{X}$

Keterangan :

$\mathrm{X}=$ Tekhnlogi Informasi

Y1 = Pengembangan Potensi

Hasil Analisis tersebut dapat dijelaskan seperti berikut :

a. Nilai konstanta sebesar 11,516 hal ini menunjukan apabila variabel teknologi informasi $(\mathrm{X})$ adalah konstan (tidak berubah) maka pengembangan potensi sebesar 11,516.

b. Koefisien regresi $X$ yaitu sebesar 0,493 hal ini menunjukan apabila variabel teknologi informasi (X) mempengaruhi variabel pengembangan potensi sebesar 0,493, artinya jika setiap peningkatan variabel teknologi informasi sebesar 1 satuan, maka akan meningkatkan pengembangan potensi sebesar 0,493 . 
Tabel 6. Hasil Analisis Regresi Linear Variabel Tekhnologi Informasi terhadap Kinerja Pegawai

\begin{tabular}{llrrc}
\hline \multicolumn{3}{c}{ Coefficients $^{\mathbf{a}}$} \\
\hline Model & \multicolumn{2}{c}{$\begin{array}{c}\text { Unstandardized } \\
\text { Coefficients }\end{array}$} & $\begin{array}{c}\text { Standardize } \\
\mathrm{d} \\
\text { Coefficients }\end{array}$ \\
\cline { 3 - 5 } & & $\mathrm{B}$ & Std. Error & Beta \\
\hline 1 & (Constant) & 16.614 & 2.852 & \\
\cline { 2 - 5 } & Teknologi & .258 & .123 & .314 \\
& Informasi & & & \\
\hline
\end{tabular}

a. Dependent Variable: Pengembangan Kinerja

Sumber : data diolah dengan SPSS v20

Berdasarkan hasil output SPSS diatas maka persamaan regresi linear sederhananya dapat dirumus kan sebagai berikut :

$\mathrm{Y} 2=16,614+0,258 \mathrm{X}$

Keterangan :

$\mathrm{X}=$ Tekhnlogi Informasi

Y2 = Kinerja pegawai

Hasil Analisis tersebut dapat dijelaskan seperti berikut :

a. Nilai konstanta sebesar 16,614 hal ini menunjukan apabila variabel teknologi informasi (X) adalah konstan (tidak berubah) maka kinerja pegawai sebesar 16,614 .

b. Koefisien regresi $\mathrm{X}$ yaitu sebesar 0,258 hal ini menunjukan apabila variabel teknologi informasi (X) mempengaruhi variabel kinerja pegawai sebesar 0,258, artinya jika setiap peningkatan variabel teknologi informasi sebesar 1 satuan, maka akan meningkatkan kinerja pegawai sebesar 0,258.

\section{e. Koefisien Korelasi dan Uji Determinasi}

Tabel 7. Hasil Uji Koefisien Korelasi dan Uji Determinasi

\begin{tabular}{|c|c|c|}
\hline \multicolumn{3}{|c|}{ Model Summary } \\
\hline Variabel & Koefisien Korelasi (R) & $\begin{array}{c}\text { Uji Determinasi ( } R \\
\text { Square) }\end{array}$ \\
\hline $\begin{array}{l}\text { Tekhnologi Informasi } \\
\text { terhadap Pengembangan } \\
\text { Potensi }\end{array}$ & 0,626 & 0,392 \\
\hline $\begin{array}{lr}\text { Tekhnologi } & \text { Informasi } \\
\text { terhadap } & \text { Kinerja } \\
\text { Pegawai } & \\
\end{array}$ & 0,314 & 0,099 \\
\hline
\end{tabular}

Sumber : data diolah dengan SPSS v20

Diketahui untuk nilai koefisien korelasi (R) variabel teknologi informasi sebesar 0,626. Maka dapat disimpukan bahwa terjadi hubungan positif yang kuat antara teknologi informasi terhadap pengembangan potensi koefisien determinasi ( $R$ Square) yang diperoleh sebesar 0,392 itu menunjukan bahwa teknologi informasi (X1) mempengaruhi variabel pengembangan potensi (Y1) sebesar 39,2\% dan untuk 60,8\% sisanya dipengaruhi oleh variabel yang tidak di teliti dalam penelitian ini. 
Nilai koefisien korelasi (R) variabel teknologi informasi sebesar 0,314, Maka dapat disimpukan bahwa terjadi hubungan positif yang rendah antara teknologi informasi terhadap kinerja pegawai. Koefisien determinasi ( $R$ Square) yang diperoleh sebesar 0,099 itu menunjukan bahwa teknologi informasi (X1) mempengaruhi variabel kinerja pegawai (Y2) sebesar 9,9\% dan untuk 90,1\% sisanya dipengaruhi oleh variabel yang tidak di teliti dalam penelitian ini.

\section{f. Uji signifikansi (uji t)}

Tabel 8. Hasil Uji t Tekhnologi Informasi terhadap Pengembangan Potensi

\begin{tabular}{|c|c|c|c|}
\hline \multicolumn{4}{|c|}{ Coefficients $^{\mathbf{a}}$} \\
\hline Mode & & $\mathrm{T}$ & Sig. \\
\hline \multirow[t]{2}{*}{1} & (Constant) & 5.137 & .000 \\
\hline & $\begin{array}{l}\text { Teknologi } \\
\text { Informasi }\end{array}$ & 5.082 & .000 \\
\hline
\end{tabular}

a. Dependent Variable: Pengembangan

Potensi

Sumber : data diolah dengan SPSS v20

Dari tabel uji t diatas diketahui variabel teknologi informasi (X) berpengaruh secara postif dan signifikan terhadap pengembangan potensi. Hal terilihat dari siginifikan teknologi informasi $(\mathrm{X}) 0,000<0,05$ dan nilai $\mathrm{t}$ tabel $=\mathrm{t}(\alpha / 2 ; \mathrm{n}-\mathrm{k}-1=\mathrm{t}(0,05 / 2 ; 44-2-1)=$ $(0,025 ; 39)=2,022$. Berarti nilai hitung lebih besar dari t tabel $(5,082>2,022)$, maka H1 di terima.

Tabel 9. Hasil Uji t Tekhnologi Informasi terhadap Kinerja Pegawai

\begin{tabular}{llll}
\hline \multicolumn{4}{c}{ Coefficients $^{\mathbf{a}}$} \\
\hline Model & & $\mathrm{T}$ & Sig. \\
& & & \\
\hline \multirow{2}{*}{1} & (Constant) & 5.826 & .000 \\
\cline { 2 - 4 } & $\begin{array}{l}\text { Teknologi } \\
\text { Informasi }\end{array}$ & 2.094 & .043 \\
\hline
\end{tabular}

a. Dependent Variable: Pengembangan

Kinerja

Sumber : data diolah dengan SPSS v20

Dari tabel uji t diatas diketahui variabel teknologi informasi $(\mathrm{X})$ berpengaruh secara postif dan signifikan terhadap kinerja pegawai. Hal terilihat dari siginifikan teknologi informasi $(\mathrm{X}) 0,043<0,05 \mathrm{Dan}$ nilai $\mathrm{t}$ tabel $=\mathrm{t}(\alpha / 2 ; \mathrm{n}-\mathrm{k}-1=\mathrm{t}(0,05 / 2 ; 44-2-1)=$ $(0,025 ; 39)=2,022$. Berarti nilai $t$ hitung lebih besar dari t tabel $(2,094>2,022)$, maka H2 di terima.

\section{KESIMPULAN}

Berdasarkan analisis data dan pembahasan hasil penelitian, peneliti menarik kesimpulan bahwa penggunaan teknologi informasi berpengaruh signifikan terhadap pengembangan potensi pegawai di BPMDES Kabupaten Bima, Artinya, Semakin tinggi penggunaan teknologi informasi maka dapat meningkatkan potensi Pegawai. Serta Penggunaan teknologi informasi berpengaruh signifikan terhadap kinerja pegawai di BPMDES Kabupaten Bima, Artinya, semakin tinggi penggunaan teknologi informasi maka kinerja pegawai akan semakin meningkat. 


\section{DAFTAR PUSTAKA}

Hasibuan, M. S. P. (2016). Manajemen Sumber Daya Manusia. Bumi Aksara.

Muzakki, M. H., Susilo, H., \& Yuniarto, S. R. (2016). Pengaruh Penggunaan Teknologi Informasi Terhadap Kinerja Karyawan (Studi Pada Karyawan PT. TELKOM Pusat Divisi Regional V Surabaya). Jurnal Administrasi Bisnis (JAB), Vol. 39 No. 2, 39(2), 169-175.

Nurariansyah, I. (2019). Pengaruh Teknologi Informasi Terhadap Kinerja Pegawai Dengan Kepuasan Kerja Sebagai Variabel Mediasi Pada Kantor Wilayah Badan Pertanahan Nasional Provinsi Sulawesi Selatan. Jurnal ASSETS, 8(5), 55.

Nurhasannah. (2017). Analisis Layanan Bimbingan Dan Konseling Tentang Potensi Diri Pada Peserta Didik Kelas Xi Sma Negeri 6 Pontianak. Jurnal Untan.

Permata, D. N., Lambey, L., \& Tangkuman, S. (2017). Analisis Penerapan Sistem Informasi Akuntansi Pembelian Suku Cadang Pada Pt. Hasjrat Abadi Sudirman Manado. Going Concern : Jurnal Riset Akuntansi, 12(2), 905-916.

Pristyadi, B., \& S, Santoso, M. R. . (2019). Pengaruh Motivasi Kerja, Kepemimpinan, Pendidikan Dan Pelatihan Serta Kepuasan Kerja Terhadap Kinerja Karyawan Tetap Di Rumaah Sakit Grha Husada. Manajerial, 6(01), 25.

Sugiyono. (2016). Metode Penelitian Kuantitatif Kualitatif dan R\&D. In Bandung: Alfabeta.

Supriatna, A., \& Sutisna, M. (2019). Pengaruh Pelatihan Kerja Terhadap Kinerja Karyawan (Studi Kasus PDAM Tirta Bumi Wibawa Kota Sukabumi). Journal of Chemical Information and Modeling, 53(9), 1689-1699.

Wahyuni, T. (2018). Pengaruh Penerapan Teknologi Informasi Terhadap Kinerja Karyawan Dengan Kemampuan Pengguna Sebagai Variabel Moderasi Pada PD. BPR Bank Jombang Kantor Pusat. 14-39. 